\title{
Phase constitution, magnetic ordering and microstructure of the $\mathrm{LaFe}_{11.0} \mathrm{Co}_{0.8} \mathrm{Si}_{1.2}$ alloy
}

\author{
P. Gębara ${ }^{1}$, P. Pawlik ${ }^{1}$, J. J. Wysłocki ${ }^{1}, Z$. Bałaga ${ }^{2}$, K. Pawlik $^{1}$ and M. Szwaja ${ }^{1}$ \\ ${ }^{1}$ Institute of Physics, Częstochowa University of Technology, Al. Armii Krajowej 19, 42-200 Częstochowa, Poland \\ ${ }^{2}$ Institute of Materials Engineering, Częstochowa University of Technology, Al. Armii Krajowej 19, \\ 42-200 Częstochowa, Poland
}

\begin{abstract}
Microstructure and phase constitution of the $\mathrm{LaFe}_{11.0} \mathrm{Co}_{0.8} \mathrm{Si}_{1.2}$ bulk and ribbon samples in as-cast state and after annealing, were studied. For both samples in as-cast state the dominant dendritic $\alpha$-Fe phase was formed. Annealing of the samples resulted in homogenization of the microstructure and change of the phase constitution. The heat treatment resulted in development of almost single-phase of the $\mathrm{NaZn}_{13}$-type structure identified as $\mathrm{LaFe}_{11.0} \mathrm{Co}_{0.8} \mathrm{Si}_{1.2}$ with minor fraction of the $\alpha$-Fe. The evolution of microstructure and phase constitution was verified by EDX analysis and Mössbauer spectroscopy.
\end{abstract}

\section{Introduction}

Conventional refrigerators working on gas transformations have negative impact on the natural environment. More friendly alternative is a cooling process that utilizes giant magnetocaloric effect (GMCE) $[1,2]$. Especially important group of materials that can be used in such devices are those, which reveal both the structural phase transition and the second order transition from ferro- to paramagnetic state near the Curie point $T_{C}$. These both effects have an important influence on the magnetic entropy change $\left|\Delta \mathrm{S}_{\mathrm{M}}\right|[3,4]$. Well known and widely studied alloy was the $\mathrm{Gd}_{5} \mathrm{Ge}_{2} \mathrm{Si}_{2}$, discovered by Pecharsky and Gschneidner in 1997, for which magnetic entropy change reach up to $18.5 \mathrm{~J} \mathrm{~kg}^{-1} \mathrm{~K}^{-1}$ in external magnetic field change of $5 \mathrm{~T}$ around Curie point of $276 \mathrm{~K}$ [5]. However this alloy is relatively expensive for commercial applications, due to high content of Gd and rigorous conditions of processing. Promising candidates for magnetocaloric applications are the rare-earthtransition metal compounds $[6,7]$. The $\mathrm{La}(\mathrm{Fe}, \mathrm{Si})_{13}$-type alloys have been intensively studied, for their possibility of applications as active elements in magnetic refrigerant due to relatively low price and specific magnetic properties. The crystal structure bases on cubic $\mathrm{NaZn}_{13}-$ type elementary cell (of the space group Fm3c) [8,9]. In this unit cell the La occupy $8 \mathrm{a}$ sites, while $\mathrm{Fe}$ atoms are randomly distributed between $8 \mathrm{~b}$ and $96 \mathrm{i}$ sites. Magnetocaloric effect is observed in wide range of temperatures from 195 to $330 \mathrm{~K}$ and depends on the alloy composition [10,11]. The largest magnetic entropy change was measured for $\mathrm{LaFe}_{11.8} \mathrm{Si}_{1.2}$ alloy, for which $\left|\Delta \mathrm{S}_{\mathrm{M}}\right|$ reaches $31 \mathrm{~J}(\mathrm{~kg} \mathrm{~K})^{-1}$ at $\mu_{0} \Delta \mathrm{H} \sim 5 \mathrm{~T}$ around $202 \mathrm{~K}$
[12]. Such good magnetocaloric properties were due to the transition from ferro- to paramagnetic state, accompanied by the change of the lattice parameter of the $\mathrm{La}(\mathrm{Fe}, \mathrm{Si})_{13^{-}}$type phase around $\mathrm{T}_{\mathrm{C}}$. The admixture of $\mathrm{Co}$ resulted in the increase of the Curie point thus leading to the shift of maximum of $\left|\Delta \mathrm{S}_{\mathrm{M}}\right|$ to $\sim 280 \mathrm{~K}$ [13]. The aim of present work was to study the phase constitution and microstructure of the $\mathrm{LaFe}_{11.0} \mathrm{Co}_{0.8} \mathrm{Si}_{1.2}$ alloy produced in a form of bulk and ribbon samples.

\section{Experimental}

The ingot samples of the $\mathrm{LaFe}_{11.0} \mathrm{Co}_{0.8} \mathrm{Si}_{1.2}$ alloy were obtained by arc-melting of high purity elements in an Ar atmosphere. Master alloy was prepared for stoichiometric composition corresponding the $\mathrm{LaFe}_{11.0} \mathrm{Co}_{0.8} \mathrm{Si}_{1.2}$ phase. Due to high loss of La during arc-melting the 15 wt.\% excess of La was used. The ribbon samples were meltspun under the Ar atmosphere with the linear velocity of the copper wheel of $\sim 35 \mathrm{~m} / \mathrm{s}$. Both bulk and ribbons samples were sealed-off in a quartz tubes under low pressure of $\mathrm{Ar}$ and annealed at $1323 \mathrm{~K}$ for 24 hours in case of ribbon and for 28 days for bulk samples. X-ray diffraction data were measured by Bruker D8 Advance diffractometer with $\mathrm{CuK} \alpha$ radiation. Simulations of elementary cell and theoretical X-ray patterns were performed using PowderCell 2.4 software [13]. Mössbauer spectra were measured using Polon mössbauer spectrometer with a ${ }^{57} \mathrm{Co}: \mathrm{Rh}$ source in conventional transmission geometry. The samples were subjected to the mechanical polishing and etching for $3 \mathrm{~s}$ in $0.5 \%$ Nital solution. Microstructures and element

This is an Open Access article distributed under the terms of the Creative Commons Attribution License 2.0, which permits unrestricted use, distribution, and reproduction in any medium, provided the original work is properly cited. 
distributions in both the as-cast and annealed bulk specimens were revealed using metallographic microscope and scanning electron microscope SEM JEOL JSM 6610LV equipped with the energy dispersive $\mathrm{X}$-ray spectrometer (EDX).

\section{Results and discussion}

The X-ray diffractions measured for as-cast bulk and ribbon samples of the $\mathrm{LaFe}_{11.0} \mathrm{Co}_{0.8} \mathrm{Si}_{1.2}$ alloy togheter with the calculated theoretical diffraction patterns, are shown in figure 1.
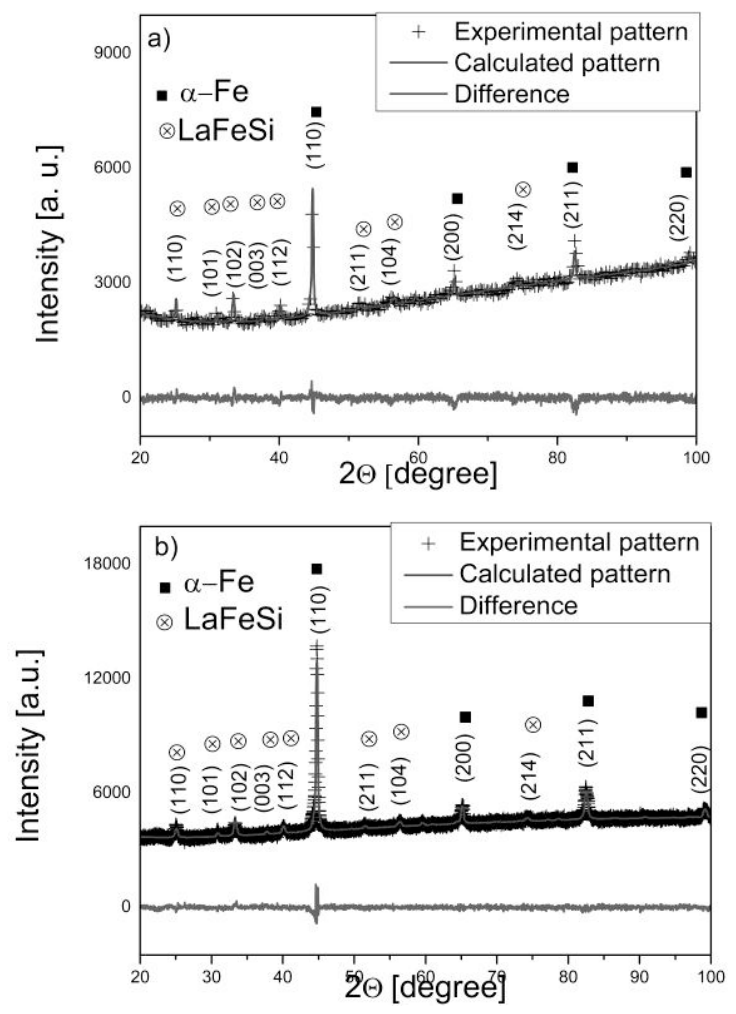

Fig. 1. X-ray diffraction patterns of the $\mathrm{LaFe}_{11.0} \mathrm{Co}_{0.8} \mathrm{Si}_{1.2}$ alloy measured for as-cast bulk (a) and ribbon (b) samples with calculated theoretical X-ray patterns.

The XRD analysis shown presence of dominant $\alpha$-Fe phase together with minor fraction of tetragonal LaFeSi phase ( $\mathrm{P} 4 / \mathrm{nmm}$ space group). Calculation of the volume fractions of constituent phases shown that $\alpha$-Fe takes $\sim 69$ vol. $\%$ of bulk sample and $\sim 82$ vol. $\%$ of ribbon. Additionally, the lattice constants for the $\alpha$-Fe phase of $\mathrm{a}=2.86 \AA$, and for the LaFeSi phase of $\mathrm{a}=4.09 \AA$ and $\mathrm{c}=$ $7.14 \AA$, were determined. The XRD patters of the $\mathrm{LaFe}_{11.0} \mathrm{Co}_{0.8} \mathrm{Si}_{1.2}$ alloy subjected to annealing at $1323 \mathrm{~K}$ for 28 days in case of bulk sample and 24 hours in case of ribbon, together with calculated theoretical diffractions are shown in figure 2. Heat treatment of the samples resulted in formation of dominant $\mathrm{LaFe}_{11.0} \mathrm{Co}_{0.8} \mathrm{Si}_{1.2}$ phase and small amount of the $\alpha$-Fe. For bulk and ribbon samples respective contributions from the $\mathrm{LaFe}_{11.0} \mathrm{Co}_{0.8} \mathrm{Si}_{1.2}$ phase were 96 vol.\% and 91 vol.\%. Similar values of the lattice constants of $11.49 \AA$ and $11.50 \AA$, respectively were determined for both bulk and ribbon samples. The remaining $\alpha$-Fe takes the rest of the samples. The calculated lattice constant for the $\alpha-\mathrm{Fe}$ phase was the same as for the as-cast samples.
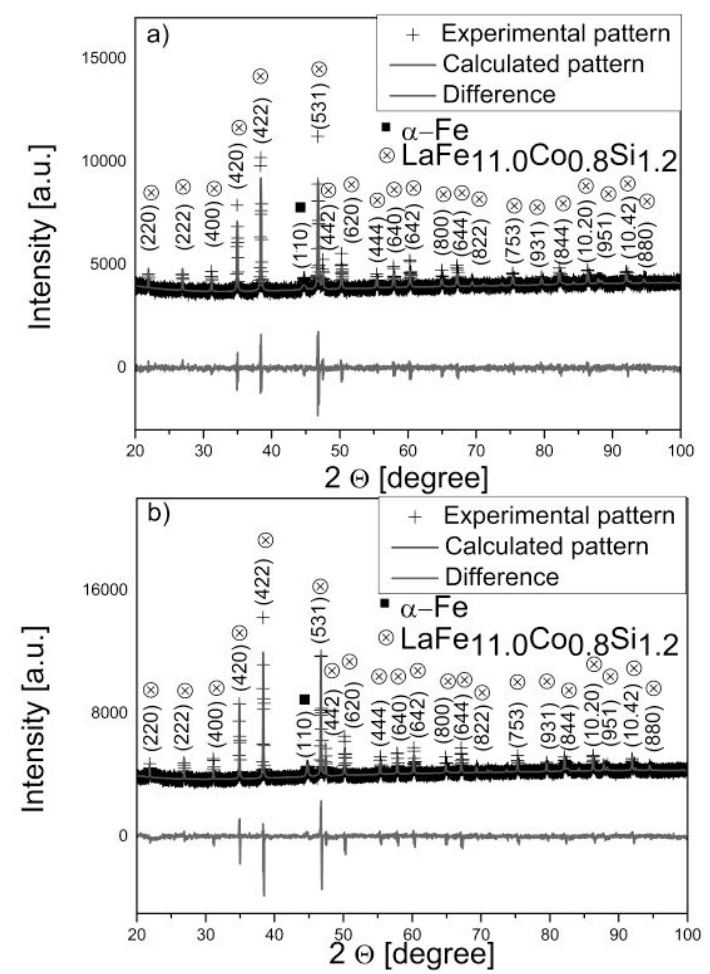

Fig. 2. X-ray diffraction patterns measured for the $\mathrm{LaFe}_{11.0} \mathrm{Co}_{0.8} \mathrm{Si}_{1.2}$ alloy bulk samples annealed for 28 days (a) and ribbon samples for 24 hours (b) annealed at $1323 \mathrm{~K}$, together with calculated theoretical $\mathrm{X}$-ray diffractions.

Microstructure of the $\mathrm{LaFe}_{11.0} \mathrm{Co}_{0.8} \mathrm{Si}_{1.2}$ alloy bulk and ribbon samples in as-cast state are shown in figure 3 . In both samples dendritic microstructure was revealed. Much finer dendrites were formed for ribbon, than those for the bulk specimen. Such differences are due to a difference in the cooling conditions during processing bulk and ribbon samples. The microstructures of samples subjected to annealing at $1323 \mathrm{~K}$ are shown in figure 4 . It was revealed that long time heat treatment resulted in homogenization of their microstructures.

In order to confirm the phase transformation accompanied by the change of microstructure, during annealing of both ribbon and bulk specimens, the SEM equipped with EDX was used. In figures 5 and 6 the SEM micrographs together with the maps of constituent element distributions for bulk sample in as-cast state and subjected to annealing at $1323 \mathrm{~K}$ for 28 days are presented. Occurrence of particular element in the observed area was indicated by the bright color. It was confirmed that dendrites in as-cast samples are formed by the $\alpha-\mathrm{Fe}$ phase, while other alloy components were expelled into the dendrite arm spacing. Unlike other elements cobalt was spread uniformly over entire volume of the samples, suggesting that it modifies $\alpha$-Fe formed during solidification of the alloy. The high temperature annealing resulted in solid state diffusion of constituent elements thus leading to homogenization of the microstructure and change of the phase constitution. 

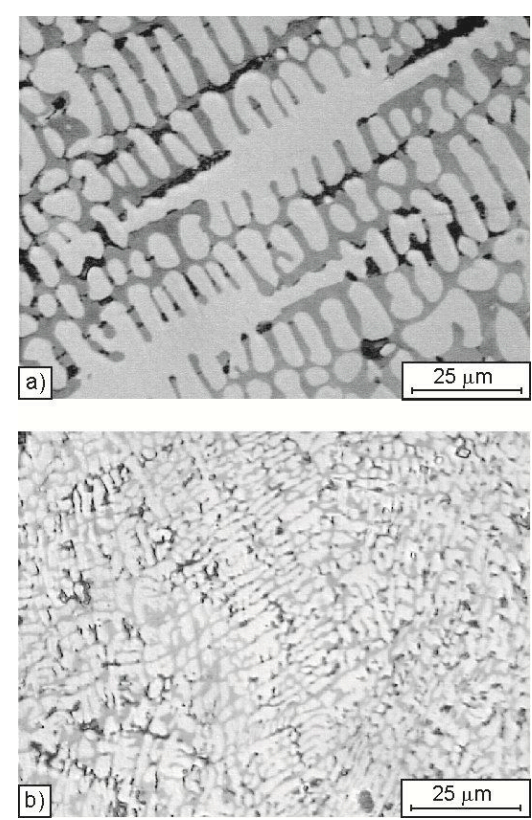

Fig. 3. Microstructures of the as-cast bulk (a) and ribbon (b) samples of the $\mathrm{LaFe}_{11.0} \mathrm{Co}_{0.8} \mathrm{Si}_{1.2}$ alloy.
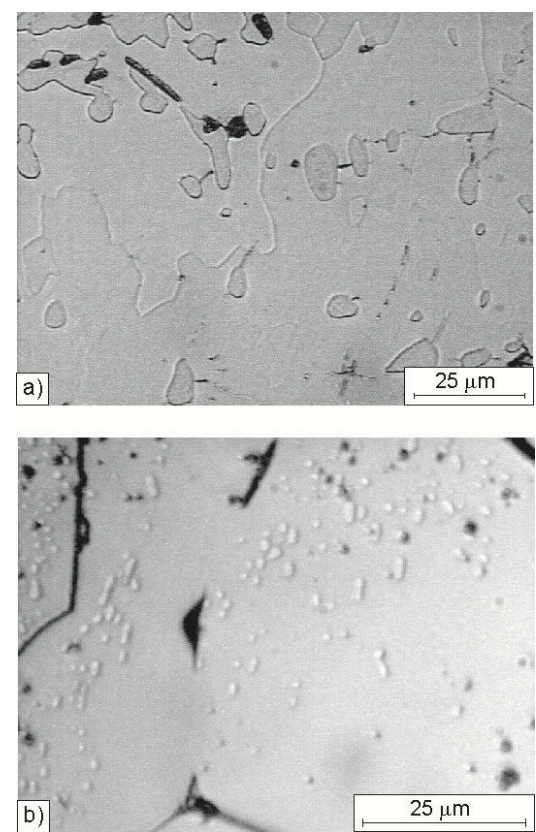

Fig. 4. Microstructures of the $\mathrm{LaFe}_{11.0} \mathrm{Co}_{0.8} \mathrm{Si}_{1.2}$ alloy bulk sample annealed at $1323 \mathrm{~K}$ for 28 days (a) and ribbon sample annealed at $1323 \mathrm{~K}$ for 24 hours (b).

The Mössbauer spectra for bulk and ribbon samples of the $\mathrm{LaFe}_{11.0} \mathrm{Co}_{0.8} \mathrm{Si}_{1.2}$ alloy in as-cast state are shown in figure 7. In the Mössbauer spectra analysis the contribution from the $\alpha$-Fe phase was represented by a single sextet line for which the induction of hyperfine field $\mathrm{B}_{\mathrm{hf}}=33.1 \mathrm{~T}$. Furthermore, another sextet line representing contribution from the ferromagnetic $\mathrm{LaFeSi}$ phase was incorporated. For complete fitting additional doublet line was introduced, which suggests presence of nuclei ( $\sim$ vol.\% for bulk and $\sim 2$ vol.\% for ribbon) of the $\mathrm{LaFe}_{11.0} \mathrm{Co}_{0.8} \mathrm{Si}_{1.2}$ phase within the as-cast alloy. Contributions from ferromagnetic phases were $\sim 67$ and $\sim 29$ vol. \% for $\alpha$-Fe and LaFeSi phases, respectively. In case of ribbon slightly higher amount of the $\alpha$-Fe phase reaching $\sim 72$ vol.\% and $\sim 26$ vol. $\%$ for the LaFeSi were obtained.
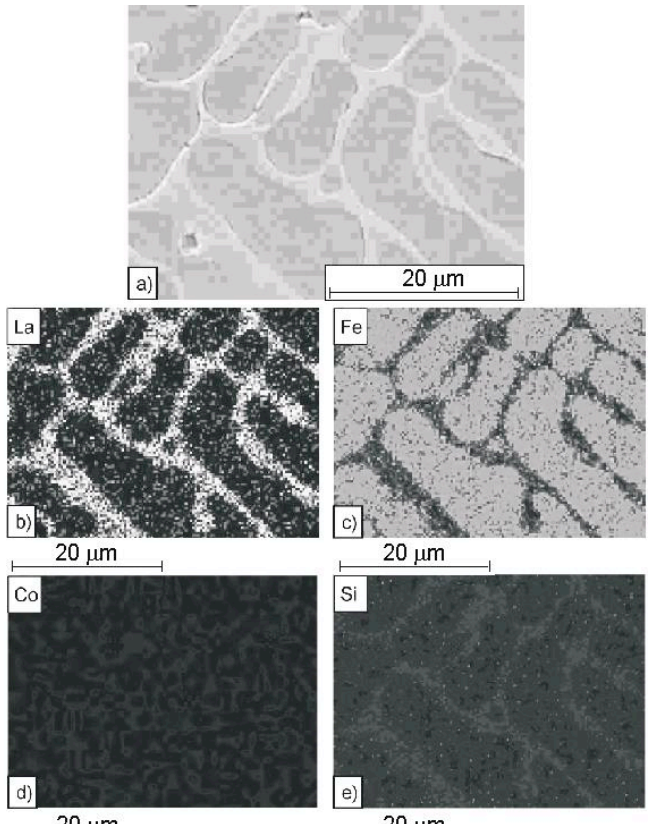

$20 \mu \mathrm{m}$

$20 \mu \mathrm{m}$

Fig. 5. Microstructure of the $\mathrm{LaFe}_{11.0} \mathrm{Co}_{0.8} \mathrm{Si}_{1.2}$ alloy bulk sample in as cast state (a) and distributions of the constituent elements (b-e).

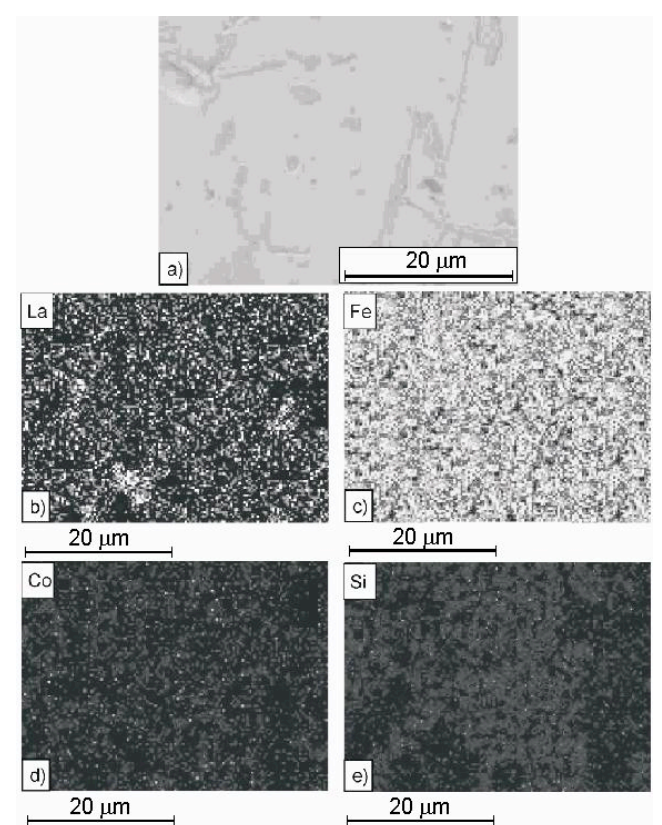

Fig. 6. Microstructure of the of the $\mathrm{LaFe}_{11.0} \mathrm{Co}_{0.8} \mathrm{Si}_{1.2}$ alloy bulk sample annealed at $1323 \mathrm{~K}$ for 28 days (a) and distributions of the constituent elements (b-e).

The rest ( $\sim$ vol.\%) was accounted for paramagnetic the $\mathrm{LaFe}_{11.0} \mathrm{Co}_{0.8} \mathrm{Si}_{1.2}$ phase. The Mössbauer spectra for annealed bulk and ribbon samples are shown in figure 8 . Here the presence of paramagnetic at room temperature $\mathrm{LaFe}_{11.0} \mathrm{Co}_{0.8} \mathrm{Si}_{1.2}$ phase was represented by a doublet of high intensity. Furthermore, additional sextet corresponding to the $\alpha$-Fe phase was incorporated. The fraction of paramagnetic phase in the sample reaches $\sim 87$ vol. $\%$ while $\sim 13$ vol. $\%$ corresponds to the $\alpha$-Fe. In the case of ribbon annealed at $1323 \mathrm{~K}$ for 24 hours, the analysis shown presence of both phases. 

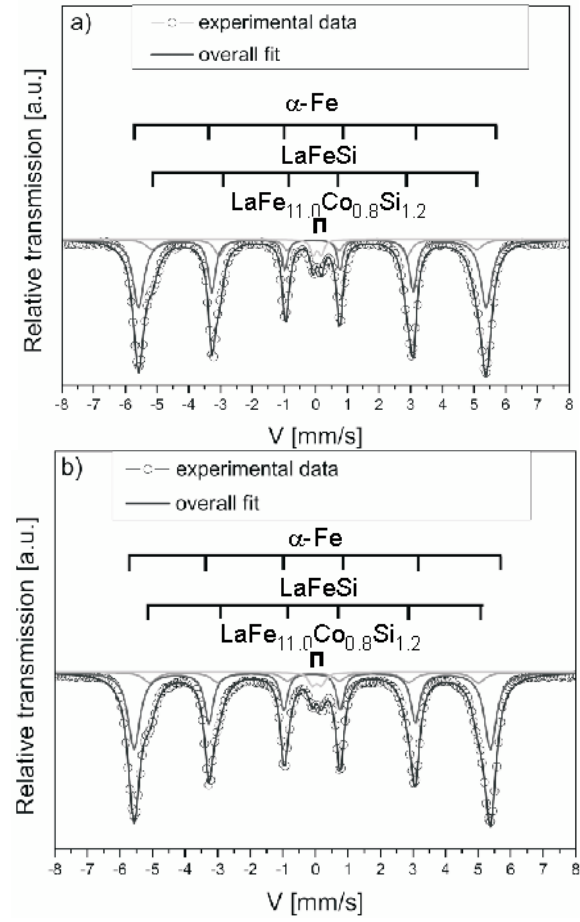

Fig. 7. Mössbauer spectra for bulk (a) and ribbon (b) samples of the $\mathrm{LaFe}_{11.0} \mathrm{Co}_{0.8} \mathrm{Si}_{1.2}$ alloy in as-cast state.
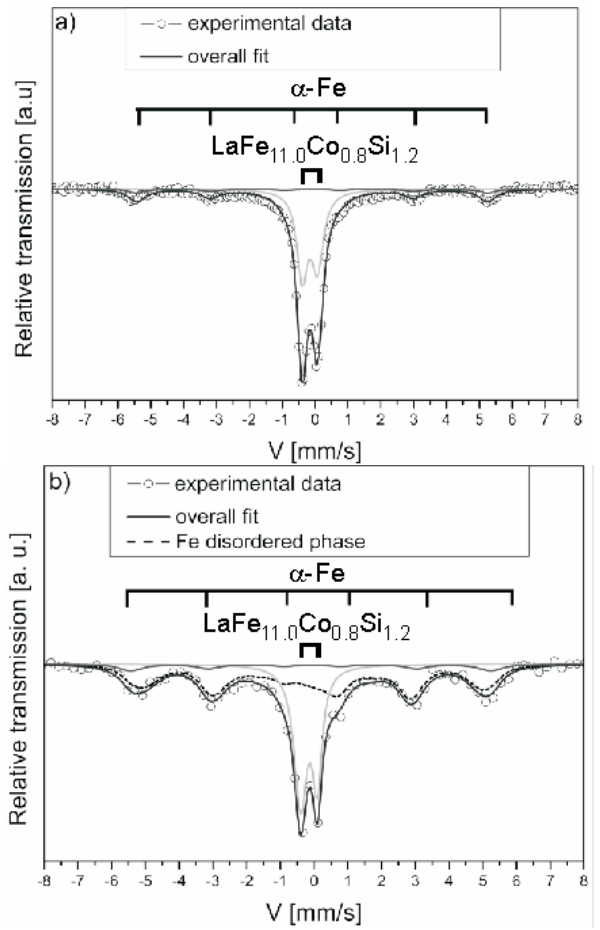

Fig. 8. Mössbauer spectra of the $\mathrm{LaFe}_{11.0} \mathrm{Co}_{0.8} \mathrm{Si}_{1.2}$ alloy subjected to heat treatment at $1323 \mathrm{~K}$ for bulk sample annealed

for 28 days (a) and ribbon annealed for 24 hours (b).

The paramagnetic $\mathrm{LaFe}_{11.0} \mathrm{Co}_{0.8} \mathrm{Si}_{1.2}$ takes about 72 vol.\% of the sample while $\alpha-\mathrm{Fe} \sim 15 \%$ of the volume. For complete fitting an additional continuous line, corresponding to a magnetically disordered phase was used. The analysis shown that this unknown phase takes $\sim 13$ vol. $\%$ of the sample. The presence of such magnetically disordered crystalline phase is due to the shortening of the annealing time. This may affect the solid state diffusion of constituent elements thus retard the formation of $\mathrm{La}(\mathrm{Fe}, \mathrm{Si})_{13}$-type phase. However further studies of this effect are required.

\section{Conclusions}

It was shown that the $\mathrm{LaFe}_{11.0} \mathrm{Co}_{0.8} \mathrm{Si}_{1.2}$ alloy in as-cast state consist of dendrites of the $\alpha$-Fe phase while the tetragonal LaFeSi phase is formed in the dendrite arm spacing. Application of melt-spinning resulted in significant reduction of $\alpha-\mathrm{Fe}$ grains, thus allowing shortening of the annealing time required for a formation of $\mathrm{LaFe}_{11.0} \mathrm{Co}_{0.8} \mathrm{Si}_{1.2}$ phase. Heat treatment of ribbons at $1323 \mathrm{~K}$ for $24 \mathrm{~h}$ resulted in formation of majority of $\mathrm{LaFe}_{11.0} \mathrm{Co}_{0.8} \mathrm{Si}_{1.2}$ phase and minor fraction of $\alpha-\mathrm{Fe}$. However, Mössbauer spectroscopy shown presence of magnetically disordered phase that emerged during annealing due to shortening of annealing time. Therefore one can conclude that even for the rapidly solidified sample with fine dendrite structure the time required for complete transformation to the $\mathrm{LaFe}_{11.0} \mathrm{Co}_{0.8} \mathrm{Si}_{1.2}$ phase has to be longer than $24 \mathrm{~h}$.

\section{Acknowledgements}

This work supported by the research project No. NN 507233040 in years 2011 - 2014 financed by Polish National Science Centre.

\section{References}

1. O. Tegus, E. Brück, K.H.J. Buschow, F.R. de Boer, Nature 415, 150 (2002)

2. V.K. Pecharsky, K.A. Gschneidner Jr., Phys. Rev. Lett. 78, 4494 (1997)

3. V.K. Pecharsky, K.A. Gschneidner Jr., J. Magn. Magn. Mater. 200, 44 (1999)

4. F.X. Hu, B.G. Shen, J.R. Sun, G.J. Wang, Appl. Phys. Lett. 80, 826 (2002)

5. V. K. Pecharsky, K. A. Gschneidner, Appl. Phys. Lett. 70, 3299 (1997)

6. K. Pawlik, I. Škorvánek, J. Kováč, P. Pawlik, J. J. Wysłocki, O. I. Bodak, J. Magn. Magn. Mater. 304, E510 (2006)

7. K. Pawlik, J. J. Wysłocki, J. Olszewski, O. I. Bodak, P. Pawlik, Nukleonika 49, S27 (2004)

8. T.T.M. Palstra, J.A. Mydosh, G.J. Nieuwenhuys, A.M. van der Kraan, K.H.J. Buschow, J. Magn. Magn. Mater. 36, 290 (1983)

9. T.T.M. Palstra, H.G.C. Werij, G.J. Nieuwenhuys, J.A. Mydosh, F.R. de Boer, K.H.J. Buschow, J. Phys. F: Met. Phys. 14, 1961 (1984)

10. F.X.Hu, B.G. Shen, J.R. Sun, Z.H. Cheng, G.H. Rao, X.X. Zhang, Appl. Phys. Lett. 78, 3675 (2001)

11. P. Gębara, P. Pawlik, I. Škorvánek, J. Marcin, J. J. Wysłocki, M. Szwaja, K. Pawlik , Acta Phys. Pol. A 121, 1285 (2012)

12. A. Yan, K. H. Müller, O. Gutfleisch, J.All. Comp. 450, 18 (2008)

13. W. Kraus, G. Nolze, POWDERCELL 2.4, D-BAM, 12205 Berlin 